\title{
A Extradição na Contemporaneidade: Breves Reflexões
}

\author{
Florisbal de Souza Del'Olmo
}

\section{INTRODUÇÃO}

Aborda-se sucintamente, no presente estudo, o instituto da extradição. Será procedida breve incursão sobre o tema, com a pretensão de contextualizá-lo, bem como tecer considerações sobre sua importância e perspectivas no dealbar do século XXI.

$O$ instituto da extradição visa a repelir o crime, sendo aceito pela maioria dos Estados, como manifestação da solidariedade e da paz social entre os povos. O conceito do mesmo e os requisitos para a sua concessão serão verificados no trabalho.

Entende-se, de antemão, que maior atenção ao instituto será notoriamente benéfica para todos os países, mediante, inclusive, uma revisão da postura da não-extradição de nacionais. Confessava Rodrigues, há mais de sete décadas, nutrir "a esperança de que dentro em breve os diversos governos, coligados na luta contra o crime, encontrarão uma fórmula racional e decorosa para, sufocando particularismos e preconceitos, proclamar o princípio da extradição dos respectivos nacionais".

O estudo será dividido em duas partes. Na primeira se ensaia uma contextualização do instituto, apresentando um escorço histórico, a importância da extradição e seu objeto, bem como uma conceituação, os requisitos para a sua concessão e a classificação mais prática.

A segunda parte procurará analisar a extradição na atualidade, tecendo considerações sobre o chamado caso

${ }^{1}$ RODRIGUES, Manoel Coelho. A Extradição no Direito Brasileiro e na Legislação Comparada. Tomo I. Rio de Janeiro: Imprensa Nacional, 1930, p. 318. 
Pinochet, amplamente divulgado pela mídia universal no período de 1998 a 2002, e que continua a merecer comentários, publicando-se nos diversos países artigos e livros pela sua transcendência no paradigma da extradição. Serão estudados, ademais, os novos delitos que desafiam as autoridades em todos os países.

\section{CONTEXTUALIZAÇÃO}

\section{A. Considerações Gerais}

O instituto da extradição apresenta interesse nos campos do Direito Constitucional, Direito Penal, Direito Processual Penal, Direito Administrativo, Direito Internacional Público e Direito Internacional Privado, além de outros segmentos das ciências jurídicas e sociais. É, portanto, ampla a sua interdisciplinaridade.

O deslocamento de indivíduos, após cometer atos tidos como ilícitos na óptica penal do meio em que foram realizados, conduziu, no passado, ao surgimento do instituto da extradição, diminuindo, segundo Mercier, as chances de impunidade, e se constituindo "dans une certaine mesure, une assurance mutuelle contre l'impunité des criminels et, par conséquent, contre le crime". ${ }^{2}$

A prática multissecular da extradição tem sido o caminho que permite o julgamento das pessoas que delinqúem e se deslocam para outros países para fugir de julgamento e condenação, afirmando Jiménez de Aréchaga que "la práctica de la extradición es el ejemplo más difundido de cooperación entre Estados en la represión de delitos". ${ }^{3}$

2 MERCIER, André. L'extradition. Recuell des Cours: Académie de Droit International. Tome 33. 1930/III, p. 178.

3 JIMENEZ DE ARECHAGA, Eduardo, VIGNALI, Heber Arbuet e RIPOLL, Roberto Puceiro. Derecho Internacional Público. V. IV. 2. ed. Montevidéu: Fundação de Cultura Universitária, 1996, p. 27. 
Entende Serrano que a extradição se constitui no "mais antigo e tradicional instrumento de cooperação internacional". ${ }^{4}$ Ela já era conhecida na Antigüidade, quando visava aos presos políticos e não aos criminosos comuns, utilização totalmente contrária, portanto, àquela dada ao instituto em nossos dias, quando não se a admite nas situações que envolvam crimes políticos.

Ao longo da História a extradição e o asilo estiveram lado a lado, concedendo-se um desses institutos e negando-se o outro, embora se deva enfatizar que a manutenção do acusado no país, pelo outorga de asilo, era a praxe. Os povos antigos consideravam o afastamento do país, já por si, um suplício para o indivíduo que se via separado de sua familia, sua religião e de seus costumes, daí a simpatia dispensada ao asilo, repelindo a extradição.

A extradição de criminosos comuns nem era cogitada nesses tempos, até porque, como refere Lisboa, eles eram os últimos perseguidos, "uma vez que sua infração afetaria a outros indivíduos e não ao soberano e à ordem pública". ${ }^{5}$

Um tratado concertado entre egípcios e hititas, em 1291 a.C., portando, entre outras, uma cláusula sobre a extradição de refugiados políticos, costuma ser referido como a mais antiga manifestação escrita sobre o instituto. ${ }^{6}$

Já o mais antigo tratado que admitiu a extradição para presos comuns surgiu em 1376, entre Carlos V, da França, e o Conde de Savóia, tendo sido assinado, quase quatro séculos após, em 1736, o primeiro tratado moderno de extradição, entre a França e os Paises Baixos, prevendo a entrega de delinqüentes comuns $\mathrm{e}$ apresentando uma lista dos crimes que ensejariam o instituto. ${ }^{7} \mathrm{~A}$ necessidade de repressão social e o superior interesse da Justiça

\footnotetext{
${ }^{4}$ BUCHO, José Manuel da Cruz et al. Cooperação Internacional Penal. V. I. Lisboa: Centro de Estudos Judiciários, 2000, p. 15.

${ }^{5}$ LISBOA, Carolina Cardoso Guimarães. A Relação Estradicional no Direito Brasileiro. Belo Horizonte: Del Rey, 2001, p. 99.

${ }^{6}$ LUZ, Nelson Ferreira. Introdução ao Direito Internacional Público. São Paulo: Saraiva, 1963, p. 199-200.
} 
inseridos nesse emblemático documento entre dois países, assevera Lisboa, evidenciam "o sentimento embrionário que existia sobre a possibilidade e a necessidade de uma justiça universal, $e$ que deve ser considerado como precursor das regras internacionais que regulam atualmente o instituto da extradição". ${ }^{8}$

O Tratado de Paz de Amiens, entre França, Inglaterra e Espanha, em 1802, foi o acordo que deu à extradição o rumo até hoje vigente, já que nele não houve cogitação de extradição de criminosos políticos. A consagração da orientação de sua inaplicabilidade nos casos de crimes políticos veio com a lei belga de $1^{\circ}$ de outubro de 1833 que excluiu de seu alcance, em termos definitivos, os criminosos políticos.

\section{Importância e Objeto da Extradição}

Assume a extradição a cada dia maior importância ante o espírito de repulsa à delinqüência que se generaliza entre os povos, mormente entre os que vivenciam saudáveis regimes democráticos. Desaparece, gradativamente, por outro lado, o exagerado pudor de considerar o instituto como invasivo à soberania do país que o concede. Dardeau de Carvalho pondera não haver como "recusar à extradição o caráter de dever internacional, cujo cumprimento, longe de afetar a soberania dos Estados, constitui clara afirmação de soberania, revelado pelos condicionamentos a que a entrega está submetida". ${ }^{9}$

Sobre o instituto continuam tempestivas estas observações de Mercier: "L'importance de l'extradition est attestée soit par le chiffre considérable d'extraditions accusé par les statisques, soit par le nombre toujours croissant des traités bilatéraux

7 MELLO, Celso D. de Albuquerque. Curso de Direito Internacional Público. 13. ed. Rio de Janeiro: Renovar, 2001, p. 978.

${ }^{8}$ LISBOA, Carolina Cardoso Guimarães. A Relação Estradicional no Direito Brasileiro. Belo Horizonte: Del Rey, 2001, p. 100 (rodapé).

9 DARDEAU DE CARVALHO, A. Situação jurídica do estrangeiro no Brasil. 1. ed. São Paulo: Sugestões Literárias, 1976, p. 134. 
d'extradition, ainsi par que les lois internes relatives à cette matière et par les discussions doctrinales qu'elle suscite". ${ }^{10}$

A extradição destina-se, em tese, a crimes graves. Como o conceito de gravidade é vago, defendem alguns autores que constem nos tratados a relação dos delitos passíveis de extradição, ou que se delimite a pena mínima de tais crimes. Nessa tessitura, os tratados que o Brasil mantém com o Chile e com a Espanha não admitem a aplicação do instituto para crimes com previsão de pena de menos de um ano de prisão, enquanto os tratados do Brasil com a Bélgica, com os Estados Unidos e com a Suiça apresentam a relação dos delitos que conduzem à extradição.

Além dos crimes políticos, os delitos militares, os de opinião e os de imprensa não ensejam a extradição. Quanto aos autores de crimes de terrorismo, mesmo anteriormente aos atos de 11 de setembro de 2001 nos Estados Unidos, já vinham sendo passíveis de extradição, na maioria dos países.

Em princípio a extradição é concedida, respeitados os pressupostos do instituto, quando o indiciado ou condenado é nacional do Estado requerente. Também é admitida quando essa pessoa é nacional de terceiro país, exigindo alguns juristas que se comunique, apenas por uma questão de cortesia internacional, ao Estado de que o extraditando é nacional.

A extradição de nacional do país requerido, por outro lado é rotineiramente negada, pois está coibida na legislação de quase todos os Estados, merecendo, portanto, uma análise especial. Temse comprovado que os diversos ordenamentos jurídicos admitem somente a concessão a estrangeiros presentes em seu território.

Há quase um consenso da não-extradição de nacionais. Muitos países, inclusive o Brasil, consignam a negativa da extradição dessas pessoas no próprio texto constitucional, assim como Cuba, Guatemala, Equador e Panamá, no continente americano, e Alemanha e Portugal, entre os Estados europeus. A

10 MERCIER, André. L'extradition. Recueil des Cours: Académie de Droit International. Tome 33. 1930/III, p. 182. 
Espanha insere a proibição em lei especial e a Grécia e a Turquia o fazem via seus códigos penais. ${ }^{11}$

Constituem honrosas exceções, como países que extraditam seus nacionais, o Reino Unido e os Estados Unidos. A Colômbia acaba de se agregar a esse grupo de Estados, pois admite extraditar narcotraficantes colombianos, para julgamento nos Estados Unidos. Os países da União Européia, outrossim, extraditam nacionais para outros Estados da Comunidade. A Itália, mediante reciprocidade, admite a extradição de cidadãos italianos.

Mesmo se considerando que muitos autores, sejam de Direito Internacional, Direito Constitucional ou de outras áreas de estudo que se ocupam da extradição, omitam seu posicionamento sobre a aplicação do instituto aos nacionais, Gilda Maciel Correa Meyer Russomano, Hildebrando Accioly, Oyama César Ituassú, Rodrigo Otávio e Luís Ivani de Amorim Araújo, entre outros estudiosos brasileiros, se colocam em favor da universalidade da extradição, sem excluir os nacionais do Estado requerido. Verificase, pelo exposto, flagrante paradoxo: enquanto a doutrina é amplamente majoritária em favor da extradição de nacionais, as legislações dos países, na quase totalidade, persistem na nãoinclusão do instituto nos seus ordenamentos jurídicos.

Ademais, embora defendida pela maioria dos doutrinadores nacionais, a extradição de brasileiros não tem sido acolhida por nossa legislação. Apenas por breve período, com a vigência a Lei $n^{\circ} 2.416$, de 28 de junho de 1911, foi ela admitida nos casos em que o país requerente, por lei ou tratado, assegurasse reciprocidade de tratamento ao Brasil (art. $1^{\circ}, \S 1^{\circ}$ da citada lei). ${ }^{12}$

Já Beviláqua enfatizava que "para conceder a extradição pedida não deve o Estado preocupar-se com a nacionalidade do criminoso". ${ }^{13}$ Entendia o mestre que o juiz natural do delinqüente é o do local no qual foi a lei infringida, que é direito do Estado punir as pessoas que atentam contra a ordem jurídica em seu território e

i1 VIERA, Manuel Adolfo e GARCÍA ALTOLAGUIRRE, Carlos. Extradición. Montevideo: Fundación de Cultura Universitaria, 2001, p. 175. 
que não se põe em jogo a dignidade nacional ao extraditar um nativo. ${ }^{14} \mathrm{~A}$ maior facilidade em se obterem as provas no local do ato delituoso e o fato de serem as leis repressivas locais mais eficazes conduzem, segundo Russomano, a uma melhor distribuição da justiça criminal. ${ }^{15}$

\section{B. O Instituto da Extradição}

A extradição visa a repelir o crime, sendo aceita pela maioria dos Estados, como manifestação da solidariedade e da paz social entre os povos. O conceito da mesma e os requisitos para a sua concessão serão verificados a seguir.

\section{Conceito e Requisitos}

Jiménez de Aréchaga conceitua a extradição como sendo "el procedimiento por el cual una persona acusada o convicta de un delito conforme a la ley de un Estado es arrestada en outro y devuelta para ser enjuiciada o castigada". ${ }^{16}$ Tredinnick, por seu turno, define-a como "el acto jurídico-administrativo en que un individuo acusado, bajo fundadas razones, como culpable de un crímen o delito, es entregado en forma oficial al Estado requirente, que es, sin sombra de dudas, competente para juzjarlo y sancionarlo". ${ }^{17}$

Para De Vabres "l'extradition est le fait, par un gouvernement, de remettre un individu au gouvernement d'un autre

12 BRIGGS, Arthur. Extradição de Nacionaes e Estrangeiros. Rio de Janeiro: Imprensa Nacional, 1919, P. 3.

13 BEVILÁQUA, Clóvis. Direito Público Internacional. Tomo II. Rio de Janeiro: Livraria Francisco Alves, 1911, p. 135.

${ }_{14}$ BEVILÁQUA, Clóvis. Direito Público Internacional. Tomo II. Rio de Janeiro: Livraria Francisco Alves, 1911, p. 137-138.

${ }^{15}$ RUSSOMANO, Gilda Maciel Corrêa Meyer. A Extradição no Direito Internacional e no Direito Brasileiro. 3. ed. São Paulo: Ed. Revista dos Tribunais, 1981, p. 1. ${ }_{16}$ JIMENEZ DE ARECHAGA, Eduardo, VIGNALI, Heber Arbuet e RIPOLL, Roberto Puceiro. Derecho Internacional Público. V. IV. 2. ed. Montevidéu: Fundação de Cultura Universitária, 1996, p. 27. 
Etat, pour qu'il soit jugé par ses tribunaux, ou, s'il a déjà été jugé, pour qu'il subisse la peine dont il a été frappé". ${ }^{18}$ Entre os autores brasileiros, por fim, Rezek conceitua extradição como "a entrega por um Estado a outro, e a pedido deste, de indivíduo que em seu território deva responder a processo penal ou cumprir pena". ${ }^{19}$ Tratase, como se observa, de entendimentos semelhantes e complementares, nos quais se podem identificar os parâmetros que norteiam e individualizam a extradição, distinguindo-a dos outros institutos que se ocupam da saída compulsória do estrangeiro, quais sejam, a deportação e a expulsão.

Se se fossem, outrossim, buscar fundamentos para o instituto, bastaria repetir Beviláqua, para quem a "extradição se organizou como uma cooperação dos Estados, para a defesa da ordem social contra o crime, para a defesa da vida jurídica, em sua luta contra a força desorganizadora da impiedade e da injustiça". ${ }^{20}$ Enfatiza Araújo que os Estados "devem manter entre si uma cooperação indispensável e essa cooperação se manifesta também no combate ao crime, evitando que o delinqüente encontre, porque fora do alcance da justiça do Estado cuja lei violou, a impunidade desejada". ${ }^{21}$

Russomano efetuou, com rara propriedade, percuciente estudo sobre as condições da extradição, catalogando os requisitos exigidos para a concessão do instituto, os delitos determinantes da mesma e as pessoas passiveis de extradição. Identificou, então, como requisitos necessidades referentes à reciprocidade, ao lugar e à data da infração, à punibilidade do fato, à inexistência de prescrição, à natureza do juízo e aos principios do non bis in idem, da especialidade e da competência. Nos delitos

17 TREDINNICK, Fellpe. Derecho Internacional Público y Relaciones Internacionales. 3. ed. La Paz: Los Amigos del Libro, 2000, p. 203.

18 DE VABRES, Donnedieu. Traité de Droit Criminel et de Legislation Penale Comparé, 3. ed. Paris: Librairie du Recueil Sirey, 1947, p. 974.

19 REZEK, José Francisco. Direito Internacional Público: Curso Elementar. 9. ed. São Paulo: Saraiva, 2002, p. 189.

${ }^{20}$ BEVILÁQUA, Clóvis. Direito Público Internacional. Tomo II. Rio de Janeiro: Livraria Francisco Alves, 1911, p. 126. 
determinantes analisou a gravidade e a natureza das infrações, enquanto sobre as pessoas passíveis verificou a nacionalidade $e$ a condição especial do extraditando. ${ }^{22}$

Nos limites propostos por este trabalho, breves referências serão feitas aos requisitos, sem pretensão de seguir a cronologia e a exaustão da erudita mestra gaúcha.

Assim, cabe inicialmente mencionar os requisitos da especialidade ou efeito limitativo da extradição (julgamento ou cumprimento de pena pelo delito considerado, tão somente) e a identidade ou dupla incriminação (fato punivel na legislação de ambos os Estados considerados). Sobre o princípio da especialidade Silva refere a extradição supletiva (descobertos outros crimes não identificados no pedido o Estado requerido solicita permissão para o julgamento dos mesmos). ${ }^{23}$

Ademais, deve haver ausência de prescrição (tanto da ação penal como da pena) e o tribunal que irá julgar, ou que já tiver condenado, o extraditando não pode ser juízo de exceção. Não se admite o bis in idem, negando-se a extradição para quem já houver sido julgado por tribunal nacional e inocentado.

A extradição depende, outrossim, da existência de tratado entre os países considerados ou de promessa de reciprocidade. A análise dessa promessa compete exclusivamente ao poder executivo. ${ }^{24}$ Lembra Mello que os países do common law só admitem a extradição com base em tratado. ${ }^{25}$

Dada a importância do instituto na atualidade, como essencial no combate ao crime transnacional, e os princípios que o norteiam, entende-se que a concessão da extradição sem a existência de tratado está plenamente justificada, mormente se estiver albergada pela certeza de reciprocidade. O Estado que

${ }^{21}$ ARAÚJO, Luis Ivani de Amorim. Curso de direito internacional público. 10. ed. Rio de Janeiro: Forense, 2000, p. 92.

22 RUSSOMANO, Gilda Maciel Corrêa Meyer. A Extradição no Direito Internacional e no Direito Brasileiro. 3. ed. São Paulo: Ed. Revista dos Tribunais, 1981, p. 66115.

${ }^{23}$ SILVA, Roberto Luiz. Direito internacional público. 2. Ed. Belo Horizonte: Del Rey, 2002, p. 232. 
entrega um condenado ou indiciado a seu país de origem, no qual foi cometido o delito, está cumprindo um dever moral, mesmo não estando obrigado juridicamente. Contribui, assim, para a repressão da criminalidade.

Na ordem jurídica brasileira a extradição, segundo o artigo 76 da Lei n ${ }^{0} 6.815$, de 19 de agosto de 1980, o chamado Estatuto do Estrangeiro, "poderá ser concedida quando o governo requerente se fundamentar a tratado, ou quando prometer ao Brasil a reciprocidade".

\section{Classificação}

O rol de modalidades de extradição pode tornar-se extenso se se proceder a uma busca mais exaustiva na classificação do instituto. Assim, poderão ser referidas, entre outras, as extradições ativa e passiva; processual e executória; de fato e de direito; convencional e extraconvencional; espontânea e requerida; imposta e voluntária; administrativa e judicial (ou mista); condicional ou temporária; consensual ou simplificada; indireta; extradição em trânsito e reextradição. ${ }^{26}$ Algumas dessas modalidades de extradição, sem maior relevância prática, não merecem qualquer referência da maioria dos autores.

Entende-se pertinente identificar as extradições ativa e passiva e processual e instrutória pela sua transcendência em qualquer estudo do instituto. Essas modalidades, mais a que considera a extradição de fato e a de direito, são também as classificações apresentadas por Souza em sua dissertação sobre 0 instituto. ${ }^{27}$

A extradição é ativa em relação ao Estado que a requer. Nela predominam, pode-se concluir, os aspectos administrativo ou político. Tem-se verificado que a maioria dos Estados, inclusive o

${ }^{24}$ SILVA, Roberto Luiz. Direito internacional público. 2. ed. Belo Horizonte: Del Rey, 2002, p. 231.

25 MELLO, Celso D. de Albuquerque. Curso de Direito Internacional Público. 13. ed. Rio de Janeiro: Renovar, 2001, p. 959. 
Brasil, demonstram pouco interesse na repatriação dos delinqüentes nacionais evadidos do pais, tornando-se diminuto $o$ número indivíduos submetidos à essa modalidade de extradição.

Será passiva a extradição quando vista através do Estado onde se homizia o acusado ou condenado cujo pedido é feito. Salienta-se nela o viés jurisdicional. Quase todos os casos de extradição de que o Brasil foi parte encaixam-se nessa modalidade. Em contraponto, ocorre que alguns países europeus, como a Alemanha, o Reino Unido e a Suíça, por exemplo, notabilizam-se pela busca de seus indiciados ou condenados que fogem para outros países, neles predominando então a extradição ativa.

Estar-se-á diante de extradição processual, instrutória ou cognitiva sempre que o Estado requerente visa a levar seu nacional fugitivo a julgamento. Pede-se nesse caso, acentua Russomano, "a devolução daquele ao qual se atribui a autoria do delito, antes de que pese, sobre ele, o pronunciamento da sentença judicial". ${ }^{28}$

A extradição executória ou executiva tem por objetivo o cumprimento de pena já imposta pelo ordenamento jurídico do Estado requerente, depois de procedido, em todas as instâncias, o pertinente processo de julgamento.

Despiciendas se tornam maiores considerações sobre a extradição de fato - entrega sem formalidades da pessoa indiciada - até porque se pode entender tratar-se de mero caso de deportação -, e da extradição de direito - realizada segundo os ditames jurídicos - até porque, a rigor, toda extradição é de direito, considerados os parâmetros que devem sempre nortear esse processo.

Neste segmento inicial do estudo se procedeu breve contextualização da extradição, apresentando um escorço histórico do instituto, a importância do mesmo, seu objeto, conceituação, os requisitos para a concessão da extradição e a classificação da

${ }^{26}$ Ver, entre outros, RUSSOMANO, G. M. C. M. Op. cit., p. 6-14; e SILVA, R. L. Op. cit., 233-235.

27 SoUZA, Artur de Brito Gueiros. As Novas Tendências do Direito Extradicional. Rio de Janeiro: Renovar, 1998, p. 26-37. 
mesma. A seguir, na segunda parte, procurar-se-á analisar a extradição na atualidade, verificando o chamado caso Pinochet, de notória transcendência no paradigma da extradição, além de uma incursão pelos novos delitos de desafiam as autoridades e o judiciário em todos os países do globo.

\section{$\|$ - A EXTRADIÇÃO NAATUALIDADE}

A globalização da economia e a conseqüente abrangência dessa uniformização nos mais diversos aspectos da vida e das relações humanas, já se fizeram sentir no instituto da extradição, uma vez que os delitos não se contiveram nos estreitos limites dos ordenamentos jurídicos, alcançando dimensões sociológicas e geográficas que conduzem a uma tomada de posição da sociedade internacional de busca de uma frente comum contra a criminalidade e a delinqüência.

Há quase um século enfatizava Adinolfi: " $L$ 'impunità offende la comunanza ed è perciò necessario che la legge violata riacquisti il suo impero, com l' osservanza del principio giuridico che stringe armonicamente tutte le Nazioni". ${ }^{29}$ Hoje, no dealbar do século XXI, o combate à impunidade continua mais atual do que antes, e a extradição passa a exercer transcendental papel nessa caminhada em prol da solidariedade e da paz social entre os povos.

\section{A. O Caso Pinochet}

Fato ocornido em 1998, com ampla divulgação na imprensa internacional, veio modificar o entendimento sobre a extradição. Em 16 de outubro desse ano, estando hospitalizado em Londres, para procedimento cirúrgico, com passaporte diplomático, na condição de senador vitalício, o ex-ditador chileno Augusto Pinochet foi detido, na própria clínica, pela polícia britânica, em virtude de pedido de extradição, partido do juiz espanhol Baltasar Garzón,

${ }^{28}$ RUSSOMANO, Gilda Maciel Corrêa Meyer. A Extradição no Direito Internacional e no Direito Brasileiro. 3. ed. São Paulo: Ed. Revista dos Tribunais, 1981, p. 11. 
que já havia emitido um mandado de detenção internacional contra o antigo chefe de Estado andino. Pretendia o magistrado ibérico, embasando seu pedido em documentos internacionais em favor dos direitos humanos, levar Pinochet a julgamento na Espanha por delitos de genocídio, torturas e desaparições contra cidadãos espanhóis durante o governo autoritário chileno, 1973 a 1990. Nesse período de exceção, registraram-se mais de três mil mortes no Chile por perseguição política, aí incluídos os delitos que agora se procurava julgar.

Tal pedido, como se depreende, estava em flagrante desacordo com os parâmetros do instituto da extradição, pois partia de terceiro país, através de magistrado de primeira instância, e se destinava a julgar um antigo chefe de Estado. No caso, o país do qual o acusado era nacional, o Chile, de onde deveria partir o pedido de extradição, era contrário à concessão e inclusive defendeu o extraditando perante a justiça inglesa. Razões de ordem humanitária foram invocadas pelas autoridades britânicas para não dar andamento ao processo, entendendo que o octogenário acusado não teria condições de se submeter a julgamento na Espanha.

Sobre o desfecho do caso Pinochet são oportunas estas observações de Viera: "Se buscaron varias salidas, para evitar la extradición de Pinochet a España, pero resultaron todas impracticables, incluido el recurso a un arbitraje bilateral entre Madrid y Santiago de Chile, en lo que Almunia, el secretario del PSOE, no quiso colaborar. Y así, los Gobiernos de España, Chile y el Reino Unido llegaron a la única posible: la humanitaria, aprovechando la discrecionalidad, conocida desde un principio, que otorga el ordenamiento británico al ministro del Interior para, por razones humanitarias o de salud, interrumpir un procedimiento de extradición, antes de concluido, en lo que era una decisión que, al ser política, se podía no recurrir (lo que no equivale a sostener, que no se debía recurrir)". ${ }^{30}$

29 ADINOLFI, Salvatore. Diritto Internazionale Penale. Milano: Editore Libraio della Real Casa, 1913, p. 145. 
A solução dada ao caso, que provocou protestos de ativistas de direitos humanos em vários países, inclusive no Chile, redundou em abertura de processo contra Pinochet em seu país, inadmissível antes do pedido espanhol.

Uma nova postura se abre para a extradição, pois outros acusados, em situação análoga, até então imunes a pedido de extradição, podem agora ver ameaçado seu futuro de impunidade. Ditadores de diversos países, alguns ainda no exercício do poder, outros já afastados, têm contra si o registro de milhares de mortes de adversários políticos, através de fuzilamento, julgamento sumário, torturas e outras atrocidades.

O magistrado e professor português Serrano observa, com propriedade: "O Caso Pinochet, embora tenha terminado de forma frustrante (em particular para as vítimas ou familiares das vítimas), por não se ter consumado a extradição, não deixou de ter a virtualidade de gerar na opinião pública internacional um sentimento planetário de justiça, ao mesmo tempo que abriu um novo ciclo na repressão das violações de direitos humanos, ao impulsionar a utilização do instituto da extradição no combate à impunidade dos principais responsáveis politicos por tais violações." ${ }^{31}$

O desfecho do caso Pinochet trouxe novas luzes para o Direito Internacional, que busca na repressão interestatal ao crime de toda espécie, o ideal de ver julgados e punidos os delinqüentes que, em qualquer lugar, praticam suas deletérias ações. Em casos como o do ditador andino impõe-se o julgamento, pois se trata de responsáveis por perseguições e mortes de milhares de pessoas, pela só razão de se colocarem em desacordo com seus pensamentos megalomaníacos, que os induzem a se sentir donos dos destinos de seu país e da própria vida de cada um de seus nacionais.

A referência ao caso Pinochet e os ensinamentos trazidos pela corajosa ação intentada pelo magistrado espanhol e os desdobramentos da mesma, tornam atuais observações feitas por

30 VIERA, Manuel Adolfo e GARCÍA ALTOLAGUIRRE, Carlos. Extradición. Montevideo: Fundación de Cultura Universitaria, 2001, p. 310. 
Ituassú em 1986: "Hoje a exceção perdeu seu efeito, pois a segunda guerra evidenciou que ninguém foge à responsabilidade de seus crimes e a consciência do mundo civilizado repele qualquer interferência que vise proteger quem é acusado de pilhagem, matança de inocentes, crimes contra a paz, deportações, assassinatos em massa". ${ }^{32}$

\section{B. Os Desafios dos Novos Delitos}

A evolução das práticas delitivas (crime econômico, narcotráfico, lavagem de dinheiro, crime organizado, delito contra a previdência, crime contra os direitos humanos, ato de terrorismo e cibercrime) é hoje uma realidade. Em uma antevisão dessa situação, Faria alertava, nas primeiras décadas do século $X X$, que "embora as convenções sobre a extradição devam ser estritamente interpretadas, essa circunstância não torna impossivel torná-las extensivas a atos que, em razão do tempo da respectiva prática, estavam fora da sua esfera de aplicação". ${ }^{33}$

Presente a observação de Briggs, quase centenária, de que a extradição não se pode reduzir a um simples ato de assistência judiciária internacional, ${ }^{34}$ e entendendo que 0 "instituto da extradição se organizou como uma cooperação dos Estados, para a defesa da ordem social contra o crime, para a defesa da vida jurídica, em sua luta contra a força desorganizadora da impiedade e da justiça", ${ }^{35}$ como enfatizava Beviláqua, busca-se, aqui, enfatizar os novos desafios antepostos ao instituto da extradição e sua importância na luta contra os crimes de todos as espécies e em qualquer parte.

Dada a ampliação em número e em variedade das práticas delitivas em quase todos os quadrantes do planeta, surge uma disposição cada vez maior de busca de meios que inibam essas atividades. A extradição é o instituto colocado nessa caminhada

31 BUCHO, José Manuel da Cruz et al. Cooperação Internacional Penal. V. I. Lisboa: Centro de Estudos Judiciários, 2000, p.50. 
do ser humano no combate ao crime. Impõe-se, então, maior atenção e engajamento de estudiosos de Direito Penal e de Direito Internacional, bem como de todas as pessoas no alargamento do conceito da extradição, a fim de adequá-la aos novos tempos.

Já em fins do século XIX, enfatizava Grasso que quase todos os Estados "hanno regolatto la matéria con trattati specialli, i quali contengono disposizioni diverse a seconda dei bisogni degli Stati contraenti del loro modo di considerare la funzione punitiva dello Stato, sebbene, prese nel loro complesso, esse presentino um fondo di principii comuni". ${ }^{36}$ São, ademais, pertinentes as palavras de Russomano, de que "seria de desejar um número cada vez maior de tratados coletivos de extradição, a fim de que se pudesse obter a uniformização crescente das condições neles estipuladas e das formalidades que devem cercar esses atos internacionais". ${ }^{37}$

Por outro lado, com igual autoridade, Bruno afirma que o instituto está em curso de evolução e "longe ainda do seu termo, que tende a definir-se em uma lei ou tratado universal de extradição, que torne geral e uniforme a sua prática", complementando: "Temse cogitado do remédio a essa posição deficiente do instituto, com a elaboração de um Código ou de um tratado universal de extradição. É uma tendência que talvez não tarde a ser satisfeita". ${ }^{38}$

$\mathrm{Na}$ esteira desse entendimento, tornam-se tempestivas estas observações de Podestá Costa: "La extradición obedece a la necesidad de cooperar por medio de la asistencia judicial entre los Estados; pero es evidente que esta ayuda no puede ser instrumento de los intereses unilaterales y menos aún de las pasiones políticas que en un momento dado imperen en un Estado extranjero". ${ }^{39}$

32 ITUASSÚ, Oyama César. Curso de Direito Internacional Público. Rio de Janeiro: Forense, 1986, p. 318.

${ }^{33}$ FARIA, Bento de. Sobre o Direito Extradicional. Rio de Janeiro: Jacintho Ribeiro dos Santos, 1930. p. 29.

34 BRIGGS, Arthur. Extradição de Nacionaes Estrangeiros: comentários e informações sobre a Lei $n^{\circ} 2.416$, de 28 de junho de 1911, p. 19.

${ }^{35}$ BEVILÁQUA, Clóvis. Direito Público Internacional. Tomo II. Rio de Janeiro: Livraria Francisco Alves, 1911, p. 126. 
Estudando o instituto e suas perspectivas na atualidade, Viera, enfatizando que não questiona a eficácia dos tratados e convenções, nem põe em dúvida os avanços alcançados através dos mesmos, assinala que o objetivo final buscado, ainda que demore para ser atingido, é "el logro de un sistema jurídico común entre los Estados, que opere fluidamente, ya que mientras ello no sea posible, se mantendrán altos los índices de criminalidad internacional, pues el sistema de aplicación de Convenios, no deja de llevar consigo factores que restan posibilidades y que imposibilitan la desaparición de todos los obstáculos para una lucha eficaz contra la macrodelincuencia". 40

Nessa tessitura, volta à tona o tema da extradição de nacionais e sua importância no caso brasileiro. Ainda que o ordenamento jurídico do Brasil não torne impunes os nacionais que delinqúem em outro país, admitindo a extradição, para o país de origem, do brasileiro naturalizado envolvido em crime de entorpecentes ou drogas afins, e sujeitando o brasileiro nato às sanções do Código Penal, conforme preceitua o artigo $7^{\circ}, \mathrm{Il}, \mathrm{b}$, acredita-se que é chegado o momento de os legisladores do país verificarem a possibilidade de inserirem o Brasil no rol dos Estados que deixam de privilegiar delinqüentes pelo só fato de serem seus nacionais.

Um fato emblemático é a verificação de ter o Brasil sido o líder mundial absoluto em 2002 de delitos na internet, os chamados cibercrimes, que ocasionaram prejuízos de mais de quarenta bilhões de dólares norte-americanos, em sua totalidade. ${ }^{41}$ Essa difusão de delitos a partir de nosso país pode conduzir o Brasil a situações constrangedoras perante a sociedade internacional. Deve ser enfatizado que os Estados Unidos, através de lei especial, o

${ }^{36}$ GRASSO, Giacomo. Principii di Diritto Internazionale Pubblico e Privato. 3. ed. Firenze: G. Barbéra, 1896, p. 112.

37 RUSSOMANO, Gilda Maciel Corrêa Meyer. A Extradição no Direito Internacional e no Direito Brasileiro. 3. ed. São Paulo: Ed. Revista dos Tribunais, 1981, p. 43. 38 BRUNO, Aníbal. Direito Penal: parte geral. Tomo I. 4. ed. Rio de Janeiro: Forense, 1984, p. 252-253.

39 PODESTÁ COSTA, L. A. e RUDÁ, José Maria. Derecho Internacional Público. V. 1. 5. ed. Buenos Aires: TEA, 1985, p. 429. 
USA Patriot Act, surgido após os atentados de 11 de setembro de 2001 , igualou as ações dos hackers aos atos terroristas, o mesmo ocorrendo no Reino Unido, que criou o UK Terrorism Act. ${ }^{42}$

Não dispõe ainda o Brasil de legislação sobre os delitos digitais, não dispondo, outrossim, do necessário preparo de policiais especializados para prevenir e combater esses ilícitos. Ainda que se considere a dificuldade de identificação da procedência e da autoria dos cibercrimes, mesmo nos países mais avançados, a relevância dessas ações no Brasil poderá conduzir o país a situações inusitadas. Assim, eventual solicitação de extradição de cibercriminoso brasileiro para julgamento por crime estático aqui cometido mas com seus efeitos no estrangeiro, ocasionará, na atual dicção constitucional do país, a negativa da entrega, o que poderá ser entendido como acobertamento brasileiro a essa prática delitiva. Acrescente-se, ainda, que nessa hipótese, mesmo o julgamento no Brasil seria dificultado pela ausência de legislação tipificadora do fato.

\section{CONCLUSÃO}

Procurou-se analisar a extradição, instituto definido por Rodríguez y Rodríguez, como "el acto mediante el cual un Estado hace entrega de una persona refugiada en su territorio a otro Estado que la reclama por estar inculpada, procesada o convicta en éste de la comisión de un delito del orden común a fin de que sea sometida a juicio o recluida para cumprir con la pena impuesta". ${ }^{43}$

Referida por Tenório como "ato pelo qual um Estado entrega à justiça estrangeira um delinqüente ou um simples indiciado", ${ }^{44}$ a extradição é, portanto, o processo pelo qual um Estado devolve, mediante solicitação do país interessado, estrangeiro condenado ou indiciado no pais requerente. Destina-

40 VIERA, Manuel Adolfo e GARCÍA ALTOLAGUIRRE, Carlos. Extradición. Montevideo: Fundación de Cultura Universitaria, 2001, p. 36.

${ }^{41}$ STAROBINAS, Marcelo. Brasil é líder mundial em crimes na internet. Folha de S. Paulo. 20 novembro 2002, p A 12.

42 Idem, 2002, p A 12. 
se, ademais, a ilícitos penais, não sendo admitida para processos de natureza administrativa, civil ou fiscal.

Entendemos que vive o instituto da extradição, nestes primeiros anos do século XXI, momento tão importante quanto o ocorrido no final do século XVIII, quando houve a mudança de paradigma do instituto para alcançar os criminosos comuns ao invés dos acusados políticos. Hoje, com a transnacionalidade dos delitos e as nefastas conseqüências de novos crimes, bem como a ampliação das condições de se manterem impunes seus autores, através da negativa de extradição, mormente pela invocação da nacionalidade, o instituto enfrenta obstáculos que necessitam ser enfrentados.

Ao se buscarem os desafios e as perspectivas da extradição na nova óptica mundial, que se caracteriza pelo espírito de globalização e de delitos transnacionais, vem a tona a prática generalizada entre os Estados, embora com ampla rejeição pelos doutrinadores, de não-extradição de nacionais, que pode, afirma Accioly, dar lugar "a grave inconveniente, qual seja o de deixar impune o indivíduo que, condenado em país estrangeiro, se refugia no próprio país, pois que, segundo os princípios gerais do direito, esse indivíduo não poderá, ordinariamente, ser julgado segunda vez pelo mesmo delito". ${ }^{45}$

Assim, os cibercrimes, que já foram identificados como os delitos do século XXI, a lavagem de dinheiro, o crime organizado, o narcotráfico e os crimes econômicos, entre outros, impõem uma exaustiva apreciação de seus contornos e da punição de seus autores, sem excluir os nacionais do país.

Ademais, como observou Oda, a extradição jamais se constituiu em uma obrigação jurídica pelos Estados, sendo a entrega dos delinqüentes admitida, através dos séculos, como um gesto de cortesia ou de subordinação de um soberano a outro. ${ }^{46}$ Impõe-se, hoje, a mudança desse paradigma.

${ }^{43}$ DICCIONARIO de Derecho Internacional. GOMEZ-ROBLEDO VERDUZCO, Alonso e WITKER, Jorge (Coordenadores). México: Editorial Porrúa, 2001, p. 163.

44 TENÓRIO, Oscar. Direito internacional privado. V. II. 11. ed. Rio de Janeiro: Freitas Bastos, 1976, p. 396 
Embora o surgimento, durante o século $X X$, de tratados multilaterais sobre o instituto, como as Convenções de Montevidéu (1933), entre Estados americanos, e a Convenção Européia de Extradição, de 1957, continua ausente a uniformidade de regras em relação à extradição. Os tratados existentes e eficazes são, em sua quase totalidade, acordos bilaterais entre Estados, havendo divergências entre as normas e procedimentos adotados nesses documentos pelos países signatários.

Afirma Cerezo Mir que a extradição é atualmente, na opinião unânime dos autores espanhóis, uma forma de cooperação judicial internacional e não mais uma manifestação do exercício do jus puniendi do Estado que a concede. ${ }^{47}$

A presença de um Direito Extradicional, por vezes referida entre os especialistas, ainda é questionável, embora necessária a sua consolidação. $O$ alargamento do instituto da extradição pelos ordenamentos jurídicos, estendendo-o aos nacionais, e a criação de uma convenção internacional sobre a extradição se apresentam como o iter a ser seguido pelos Estados capaz de coibir a criminalidade e ampliar a harmonia entre os povos do planeta.

Esse parece ser o caminho da sociedade internacional na sua luta pela paz social e a solidariedade entre os povos. Poderse-á então vivenciar o surgimento de um Direito Internacional da Extradição ou Direito Internacional Extradicional, capaz de dirimir dificuldades e apresentar respostas para a maioria das questões levantadas pelas pessoas que cometem crimes e buscam a impunidade em outros paises.

${ }^{45}$ ACCIOLY, Hildebrando e SILVA, Geraldo Eulálio do Nascimento e. Manual de direito internacional público. 12. ed. São Paulo: Saraiva, 1996, p. 350.

45. SORENSEN, Max (Editor). Manual de Derecho Internacional Público. México: Fondo de Cultura Económica, 1998, p. 496.

47 CEREZO MIR, José. Curso de Derecho Penal Español: Parte General. Madri: Tecnos, 1976, p. 216. 


\section{REFERÊNCIAS}

ACCIOLY, Hildebrando, e SILVA, Geraldo Eulálio do Nascimento e. Manual de Direito Internacional Público. 12. ed. São Paulo: Saraiva, 1996.

ADINOLFI, Salvatore. Diritto Internazionale Penale. Milano: Editore Libraio della Real Casa, 1913.

ARAÚJO, Luis Ivani de Amorim. Curso de Direito Internacional Público. 10. ed. Rio de Janeiro: Forense, 2000.

BEVILÁQUA, Clóvis. Direito Público Internacional. Tomo II. Rio de Janeiro: Livraria Francisco Alves, 1911.

BRIGGS, Arthur. Extradição de Nacionaes e Estrangeiros: comentários e informações sobre a Lei $n^{\circ} 2.416$, de 28 de junho de 1911. Rio de Janeiro: Imprensa Nacional, 1919.

BROWNLIE, Ian. Principios de Direito Internacional Público. Tradução Maria Manuela Ferrajota et al. Lisboa: Fundação Calouste Gulbenkian, 1997.

BRUNO, Aníbal. Direito Penal: parte geral. Tomo I. 4. ed. Rio de Janeiro: Forense, 1984.

BUCHO, José Manuel da Cruz et al. Cooperação Internacional Penal. V. I. Lisboa: Centro de Estudos Judiciários, 2000.

CEREZO MIR, José. Curso de Derecho Penal Español: Parte General. Madri: Tecnos, 1976.

DARDEAU DE CARVALHO, A. Situação Jurídica do Estrangeiro no Brasil. 1. ed. São Paulo: Sugestões Literárias, 1976. 
DE VABRES, Donnedieu. Traité de Droit Criminel et de Legislation Penale Comparé. 3. ed. Paris: Librairie du Recueil Sirey, 1947.

DICCIONARIO de Derecho Internacional. GOMEZROBLEDO VERDUZCO, Alonso e WITKER, Jorge (Coordenadores). México: Editorial Porrúa, 2001.

EASTMAN, Jorge Mario. Pinochet, el Déspota que Revolucionó el Derecho Internacional. Santa Fé de Bogotá: TM Editores, 2000.

FARIA, Bento de. Sobre o Direito Extradicional. Rio de Janeiro: Jacintho Ribeiro dos Santos, 1930.

FARO JUNIOR, Luiz P. F. Direito Internacional Público. 4. ed. Rio de Janeiro: Borsoi, 1965.

GRASSO, Giacomo. Principii di Diritto Internazionale Pubblico e Privato. 3. ed. Firenze: G. Barbéra, 1896.

ITUASSÚ, Oyama César. Curso de Direito Internacional Público. Rio de Janeiro: Forense, 1986.

JIMENEZ DE ARECHAGA, Eduardo, VIGNALI, Heber Arbuet e RIPOLL, Roberto Puceiro. Derecho Internacional Público. V.I - IV. 2. ed. Montevidéu: Fundação de Cultura Universitária, 1996.

LISBOA, Carolina Cardoso Guimarães. A Relação Estradicional no Direito Brasileiro. Belo Horizonte: Del Rey, 2001.

LUZ, Nelson Ferreira. Introdução ao Direito Internacional Público. São Paulo: Saraiva, 1963. 
MATTOS, Adherbal Meira. Direito e Relações Internacionais. Belém: Editora CESUPA, 2003.

MELLO, Celso D. de Albuquerque. Curso Direito Internacional Público. 13. ed. Rio de Janeiro: Renovar, 2001.

MERCIER, André. L'Extradition. Recueil des Cours: Académie de Droit International. Tome 33. 1930/III. p.167-240.

PODESTÁ COSTA, L. A. e RUDÁ, José Maria. Derecho Internacional Público. V. 1. 5. ed. Buenos Aires: TEA, 1985.

REZEK, José Francisco. Direito Internacional Público: Curso Elementar. 9. ed. São Paulo: Saraiva, 2002.

RODRIGUES, Manoel Coelho. A Extradição no Direito Brasileiro e na Legislação Comparada. Tomo I. Rio de Janeiro: Imprensa Nacional, 1930.

RUSSOMANO, Gilda Maciel Corrêa Meyer. A Extradição no Direito Internacional e no Direito Brasileiro. 3. ed. São Paulo: Ed. Revista dos Tribunais, 1981.

- Aspectos da Extradição no Direito Internacional Público. Rio de Janeiro: José Konfino, 1960.

SILVA, Roberto Luiz. Direito Internacional Público. 2. ed. Belo Horizonte: Del Rey, 2002.

SORENSEN, Max (Editor). Manual de Derecho Internacional Público. México: Fondo de Cultura Económica, 1998.

SOUZA, Artur de Brito Gueiros. As Novas Tendências do Direito Extradicional. Rio de Janeiro: Renovar, 1998. 
STAROBINAS, Marcelo. Brasil é líder mundial em crimes na internet. Folha de S. Paulo. São Paulo, 20 novembro 2002, p A 12.

TENÓRIO, Oscar. Direito Internacional Privado. V. II. 11. ed. Rio de Janeiro: Freitas Bastos, 1976.

TREDINNICK, Felipe. Derecho Internacional Públicoy y Relaciones Internacionales. 3. ed. La Paz: Los Amigos del Libro, 1997.

VIEIRA, Manuel Adolfo e GARCIA ALTOLAGUIRRE, Carlos. La Extradición Desde sus Orígenes Hasta Nuestros Días. Montevideo: Fundación de Cultura Universitaria, 2001. 